\title{
Factors affecting the growth of Microthrix parvicella: Batch tests using bulking sludge as seed sludge
}

\author{
Niansi Fan ${ }^{\mathrm{a}, \mathrm{b}}$, Rong $\mathrm{Qi}^{\mathrm{a}, \mathrm{b}}$, Simona Rossetti ${ }^{\mathrm{c}}$, Valter Tandoi ${ }^{\mathrm{c}}$, Yingxin Gao ${ }^{\mathrm{a}, \mathrm{b}}$, Min Yang ${ }^{\mathrm{a}, \mathrm{b}, *}$ \\ a State Key Laboratory of Environmental Aquatic Chemistry, Research Center for Eco-Environmental Sciences, Chinese Academy of Sciences, Beijing 100085, China \\ ${ }^{\mathrm{b}}$ University of Chinese Academy of Sciences, Beijing 100049, China \\ c CNR, Water Research Institute, Via Reno 1, 00198 Roma, Italy
}

\section{H I G H L I G H T S}

- Population dynamics of M. parvicella and SVI variation identified the correlation between sludge settle ability and M. parvicella abundance.

- LCFA, anaerobic/aerobic alternation and low temperature are advantageous conditions for the competitive growth of $M$. parvicella.

- This study fosters physiological knowledge of M. parvicella, which lay a foundation for the subsequent pure culture of this microorganism.

\section{A R T I C L E I N F O}

\section{Article history:}

Received 24 May 2017

Received in revised form 29 July 2017

Accepted 29 July 2017

Available online 4 August 2017

Editor: Jay Gan

\section{Keywords:}

Bulking sludge

Microthrix parvicella

Carbon source

Anaerobic/aerobic alternation condition

Temperature

\section{G R A P H I C A L A B S T R A C T}

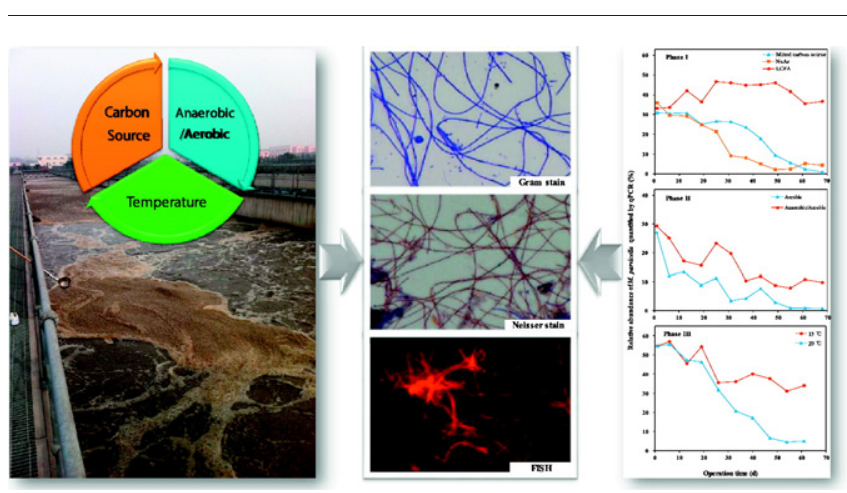

\begin{abstract}
A B S T R A C T
Sludge bulking caused by the overgrowth of filamentous bacteria, particularly Microthrix parvicella, is one of the challenges for the stable operation of municipal wastewater treatment plants (WWTPs). The driving forces for the development of sludge bulking, however, have not been well understood because of the extremely low growth rate of $M$. parvicella. In this study, batch experiments were performed using bulking sludge (sludge volume index (SVI), around $185 \mathrm{~mL} \mathrm{~g}^{-1}$ ) from a full-scale WWTP as the seed sludge to investigate the influences of carbon source, anaerobic/aerobic alternation condition and temperature on the growth of M. parvicella. The qPCR results showed that the use of oleic acid as carbon source, anaerobic/aerobic alternation treatment and low temperature $\left(13^{\circ} \mathrm{C}\right)$ were favorable conditions for maintaining the dominance of $M$. parvicella in the tested activated sludge. Under these conditions, the SVI values remained at comparatively high values of $170.5 \mathrm{~mL} \mathrm{~g}^{-1}$, $162.5 \mathrm{~mL} \mathrm{~g}^{-1}$ and $129.5 \mathrm{~mL} \mathrm{~g}^{-1}$ after operation for approximately two months, and the relative abundances of M. parvicella were $36.7 \%, 9.74 \%$ and $34.07 \%$, respectively, in comparison with the initial values of $33.04 \%$, $29.29 \%$ and $54.66 \%$. However, the relative abundances of $M$. parvicella decreased to $0.86-4.44 \%, 0.7 \%$ and $4.94 \%$, respectively, under the conditions of other carbon sources, aerobic-only treatment and a temperature of $20^{\circ} \mathrm{C}$. The FISH analysis gave a similar result. This study was performed with mixed sludge under controlled operating conditions, which provided a valuable information for the pure culture of M. parvicella and further investigations on its physiology and metabolism.
\end{abstract}

(c) 2017 Elsevier B.V. All rights reserved.

\footnotetext{
* Corresponding author at: Shuangqing Road No. 18, Haidian District, Beijing 100085, China.

E-mail address: yangmin@rcees.ac.cn (M. Yang).
} 


\section{Introduction}

Microthrix parvicella, with a hydrophobic cell surface, high intracellular storage capacity and low maintenance energy requirement, frequently causes sludge bulking in wastewater treatment plants (WWTPs) (Mamais et al., 1998; Miana et al., 2002; Slijkhuis, 1983a). Understanding the conditions favorable for the growth of $M$. parvicella have been one of the top hotspots for research on sludge bulking. Based on microautoradiography (MAR) analysis, Andreasen and Nielsen (2000) found that M. parvicella could take up long-chain fatty acids (LCFAs) under oxic, anoxic and anaerobic conditions. Mcllroy et al. (2013) constructed a metabolic model for M. parvicella based on metagenomic analysis, proposing that under anaerobic condition this organism preferentially accumulated LCFAs. On the other hand, most of the sludge bulking events have been found to occur in enhanced nutrient removal processes including at least one anaerobic/aerobic alternation cycle (Eikelboom et al., 1998; Wagner et al., 1994), particularly at times when the temperature is low (normally below $15^{\circ} \mathrm{C}$ ) (Wang et al., 2014). Nielsen et al. (2012) revealed that M. parvicella was potentially active during the entire process, taking up substrates under anaerobic conditions (but no growth) and growing in the aerobic tanks by means of either stored materials or hydrolysis products. Kumari et al. (2009a) found that M. parvicella might prefer low temperature conditions for growth.

All of the previous studies on the utilization of LCFAs were mainly based on the observations of full-scale WWTPs or gene prediction, and the effects of LCFAs on the in situ growth of $M$. parvicella have not yet been elaborated, nor those of aerobic/anaerobic alternation and low temperature. Though pure cultures of $M$. parvicella 4B and RN1 strains were acquired through the micromanipulation method (Rossetti et al., 1997; Rossetti et al., 2002), studies on the behaviors of M. parvicella using pure cultures have gained little progress. One of the big challenges is the difficulty in getting a sufficient amount of biomass for the studies of M. parvicella due to its extremely low growth rate (Rossetti et al., 2002; Sheik et al., 2016). In this study, batch experiments were carried out to explore the favorable conditions for the growth of $M$. parvicella by using bulking sludge as seed sludge under different strategies. The impacts of carbon sources, anaerobic/aerobic conditions, and temperature on the growth of $M$. parvicella were evaluated over a period of approximately two months, respectively. Multiple approaches including microscopic observation, fluorescence in situ hybridization (FISH) and real-time polymerase chain reaction ( $\mathrm{qPCR}$ ) were employed to monitor the dynamics of $M$. parvicella under various conditions over the operating period. This is the first study to investigate the integrated effects of LCFAs, aerobic/anaerobic alternation and low temperature on the competitive growth $M$. parvicella using bulking sludge, which could not only provide useful information of selective conditions for subsequent pure culture, but also take one step forward in understanding the physiology and metabolism of M. parvicella.

\section{Materials and methods}

\subsection{Source of seed sludge}

Seed sludge was collected from the aeration tank of Xiaohongmen Wastewater Treatment Plant, Beijing, China, during the bulking period $\left(\mathrm{SVI}>150 \mathrm{~mL} \mathrm{~g}^{-1}\right)$. This plant adopts the anaerobic-anoxic-oxic $\left(\mathrm{A}^{2} /\right.$ O) process (Fig. S1), designed for 193,000 population equivalents. The main operational parameters during the sampling time are summarized in Table S1. Sludge samples during moderate bulking events were collected on 26th Nov 2014 (SVI, $181.2 \mathrm{~mL} \mathrm{~g}^{-1}$ ), 11th Mar 2015 (SVI, $189.5 \mathrm{~mL} \mathrm{~g}^{-1}$ ), and 28th May 2015 (SVI, $183 \mathrm{~mL} \mathrm{~g}^{-1}$ ), respectively, brought to the laboratory within $2 \mathrm{~h}$, and immediately washed by phosphate buffer saline (PBS $1 \times$ ) solution twice before the start of experiments.

\subsection{Experimental set-up}

Three sets of experiments were designed as shown in Table 1. Phases I, II and III were used to evaluate the effects of carbon source, anaerobic/ aerobic alternation and temperature on the dynamics of $M$. parvicella separately. The experiments were performed in sequencing batch reactors (SBRs), and the running time of the three phases were 68, 67 and $61 \mathrm{~d}$, respectively.

Seed sludge was inoculated into a $500 \mathrm{~mL}$ glass bottle containing $300 \mathrm{~mL}$ synthetic influents (Tables S2-S3), and $100 \mathrm{~mL}$ fresh artificial wastewater was added into the bottle every day after the same amount of treated wastewater was decanted following 30 min sedimentation. The sludge retention time (SRT) and hydraulic retention time (HRT) for all reactors were $60 \mathrm{~d}$ and $24 \mathrm{~h}$, respectively. The long HRT was chosen to maintain sufficient COD and ammonium removal under different conditions. Besides, long HRT would result in a low sludge loading, which had been reported to be beneficial for the competitive growth of M. parvicella (Knoop and Kunst, 1998; Rossetti et al., 1994). Synthetic influents were freshly prepared every $3-4 \mathrm{~d}$ and stored at $4{ }^{\circ} \mathrm{C}$. A stock solution of oleic acid was prepared in deionized water by adding Tween $80(1: 9, \mathrm{v} / \mathrm{v})$, and heated at $60{ }^{\circ} \mathrm{C}$ for $30 \mathrm{~min}$. Tween 80 is a water-soluble liquid containing $0.22 \mathrm{~g}$ oleic acid $\mathrm{g}^{-1}$ Tween 80 (Noutsopoulos et al., 2012), which was added to promote the dissolution of oleic acid. The average chemical oxygen demand (COD), nitrogen (mainly ammonium salt, $\mathrm{NH}_{4}^{+}-\mathrm{N}$ ) and phosphorus (mainly orthophosphate, $\mathrm{PO}_{4}^{3-}-\mathrm{P}$ ) concentrations in the synthetic wastewater were adjusted to around $250 \mathrm{mg} \mathrm{L}^{-1}, 15 \mathrm{mg} \mathrm{L}^{-1}$ and $5 \mathrm{mg} \mathrm{L}^{-1}$, respectively.

The bottles were put in incubators under different conditions as shown in Table 1. For the aerobic treatment, bottles covered by sealing films with holes were shaken with a constant speed of $160 \mathrm{rpm}$. The anaerobic condition was achieved by bubbling with argon gas for at least $20 \mathrm{~min}$ and tightly sealing with a bottle cap. In the anaerobic/aerobic alternation experiment, a cycle of anaerobic condition for $8 \mathrm{~h}$ followed by aerobic condition for $16 \mathrm{~h}$ was adopted, and the last half hour of aerobic stage was taken for the sludge sedimentation. Nutrients feeding and argon inflation were carried out at 10:00 am each day.

This study was trying to verify three important assumptions for the preferential growth of filamentous bacteria: the presence of LCFAs, aerobic/anaerobic alternation and low temperature. In order to control the sampling numbers at a reasonable level, a progressive strategy was adopted to verify these three assumptions. Therefore, the selective conditions tested in each phase were chosen based on the results of the previous phase.

Table 1

The main conditions for the batch experiments.

\begin{tabular}{|c|c|c|c|c|c|}
\hline Phase & $\begin{array}{l}\text { Inoculation } \\
\text { time }^{\mathrm{a}}\end{array}$ & $\begin{array}{l}\mathrm{SVI}^{\mathrm{b}} \\
(\mathrm{mL} \\
\left.\mathrm{g}^{-1}\right)\end{array}$ & Process type $^{c}$ & $\begin{array}{l}\text { Carbon } \\
\text { source }^{\mathrm{d}}\end{array}$ & $\begin{array}{l}\text { Temperature } \\
\left({ }^{\circ} \mathrm{C}\right)\end{array}$ \\
\hline $\begin{array}{c}\text { Phase } \\
\text { I }\end{array}$ & $26 / 11 / 2014$ & 181.2 & Aerobic $(24 \mathrm{~h})$ & $\begin{array}{l}\text { Mixed } \\
\text { NaAc } \\
\text { LCFAs }\end{array}$ & 20 \\
\hline $\begin{array}{c}\text { Phase } \\
\text { II }\end{array}$ & $11 / 03 / 2015$ & 189.5 & $\begin{array}{l}\text { Aerobic }(24 \mathrm{~h}) \\
\text { Anaerobic }(8 \mathrm{~h}) \text { /Aerobic } \\
(16 \mathrm{~h})\end{array}$ & LCFAs & 20 \\
\hline $\begin{array}{l}\text { Phase } \\
\text { III }\end{array}$ & $28 / 05 / 2015$ & 183.1 & $\begin{array}{l}\text { Anaerobic }(8 \mathrm{~h}) / \text { Aerobic } \\
(16 \mathrm{~h})\end{array}$ & LCFAs & $\begin{array}{l}13 \\
20\end{array}$ \\
\hline
\end{tabular}

Note:

a The date indicates the sampling time $(\mathrm{d} / \mathrm{m} / \mathrm{y})$ of the inoculated sludge for the three phases in the initial stage.

b These values were SVI of the inoculum.

c Duplicate experiments were performed for each condition and all results were analyzed based on average values.

d Mixed carbon source included sodium carboxymethylcellulose (CMC-Na), starch, glucose and tryptone; NaAc: sodium acetate; LCFAs: long-chain fatty acids including oleic acid and Tween 80 . 


\subsection{Chemical analysis and microscopic examination}

The operating performance was monitored by taking wastewater samples twice a week for the determination of ammonium nitrogen $\left(\mathrm{NH}_{4}^{+}-\mathrm{N}\right)$, nitrate nitrogen $\left(\mathrm{NO}_{3}^{-}-\mathrm{N}\right)$, nitrite nitrogen $\left(\mathrm{NO}_{2}^{-}-\mathrm{N}\right)$, orthophosphate phosphorus $\left(\mathrm{PO}_{4}^{3-}-\mathrm{P}\right)$, sludge volume index (SVI), and mixed liquor suspended solids (MLSS) according to the Standard Methods (Eaton et al., 2005). Samples were collected and immediately filtered through $0.45 \mu \mathrm{m}$ PES membranes (Millipore, USA). In addition, operating parameters including temperature, $\mathrm{pH}$ and dissolved oxygen (DO) were measured using a thermometer and Orion Star A portable $\mathrm{DO} / \mathrm{pH}$ instrument (Thermo Scientific, USA). The DO value at the end of aerobic stage was $5-8 \mathrm{mg} \mathrm{L}^{-1}$, and that of the anaerobic stage was below $0.1 \mathrm{mg} \mathrm{L}^{-1}$. The reductive condition was also checked using a redox potential meter, and its value was around $-180 \mathrm{mV}$ at the end of anaerobic stage.

Samples used for quantification of filaments were collected once every week in duplicates from the mixed liquor. For DNA extraction, approximately $2 \mathrm{~mL}$ samples were centrifuged at $8000 \mathrm{~g}$ (Sigma Centrifuge, Germany) and the cell pellets were stored at $-20{ }^{\circ} \mathrm{C}$ until DNA extraction. For FISH analysis, $2 \mathrm{~mL}$ samples were fixed in $9 \mathrm{ml} 4 \%(\mathrm{w} /$ v) paraformaldehyde for $2 \mathrm{~h}$ at $4{ }^{\circ} \mathrm{C}$ and stored in PBS/ethanol $(1: 1, \mathrm{v} /$ v) at $-20{ }^{\circ} \mathrm{C}$ until hybridization (Marneri et al., 2009). Samples were subjected to ultrasonic oscillation several times before cell fixation in order to destroy the floc structure and obtain a better view of the filaments during microscopic observation. In addition, a small amount of fresh sludge samples were taken for microscopic observation of sludge structure. The changes of sludge floc size and structure were observed under microscopy. Predominant microorganisms were identified based on morphological features by using Gram stain (Hucker and Conn, 1923) and Neisser stain (Westlund et al., 1998). The density of filamentous bacteria in activated sludge was roughly estimated in terms of the filament index (FI) according to Jenkins et al. (1993). Filamentous bacteria abundance could be evaluated using the FI on a scale of $0-6$ representing none (0), few (1), some (2), common (3), very common (4), abundant (5) and excessive filaments (6), respectively. Activated sludge was generally considered to be in severe bulking state at $\mathrm{FI} \geq 5$.

\subsection{DNA extraction and quantitative $P C R$}

To characterize the composition of the microbial community in the sludge samples, total genomic DNA was extracted using a Fast DNA Spin Kit for Soil from MP Biomedicals following the manufacturer's instructions. Extracted DNA was amplified in a PCR Cycler (Light Cycler 96, Roche) using 341f ( $5^{\prime}-$ CCTACGGGAGGCAGCAG-3') and 534r $\left(5^{\prime}-\right.$ TTACCGCGGCTGCTGGCAC-3') primer sets (Bru et al., 2008). The amplified products were visualized on $1 \%$ agarose gel stained with ethidium bromide (the final concentration of $10 \mathrm{mg} \mathrm{mL}^{-1}$ ).

Standard plasmids carrying the target genes were obtained by utilizing TA clones and extracted using a TIANpure Mini Plasmid kit (Tiangen, China). The concentrations of the standard plasmids ( $\mathrm{ng} \mathrm{LL}^{-1}$ ) were determined with a NanoDrop ND-1000 (NanoDrop, USA), and their copy concentrations (copies $\mu \mathrm{L}^{-1}$ ) were subsequently calculated by using the following equation (Pei et al., 2006).

$$
\begin{aligned}
& \frac{\text { DNA mass concentration }\left[\mathrm{ng} \mu \mathrm{L}^{-1}\right]}{\text { DNA molecular weight }\left[\mathrm{g} \mathrm{mol}^{-1}\right]} \times\left(6.02 \times 10^{23}\right) \times 10^{-9} \\
& \quad=\text { copy concentration }\left[\text { copies } \mu \mathrm{L}^{-1}\right]
\end{aligned}
$$

Triplicate quantitative real-time PCR assays were performed for the decimally diluted standard plasmids to obtain the standard curves, with no amplification signal from two negative controls (one without primers and the other without template DNA). Duplicate assays were performed for all samples on an ABI7300 apparatus (ABI, USA) using
SYBR Green chemistry. Quantification of M. parvicella was performed by qPCR using the 16S rRNA gene primer set S-S-M.par-0828-S-21/SS-M.par-1018-A-17 (Table 2) (Kaetzke et al., 2005) and SYBR Green as the fluorescent dye with the program of $95{ }^{\circ} \mathrm{C} 10 \mathrm{~min}, 95{ }^{\circ} \mathrm{C} 15 \mathrm{~s}, 62$ ${ }^{\circ} \mathrm{C} 30 \mathrm{~s}, 60{ }^{\circ} \mathrm{C} 30 \mathrm{~s}$, and 39 cycles. The amplification was carried out in $25 \mu \mathrm{L}$ reaction mixtures containing $2 \mu \mathrm{L}$ of a $1: 10$ dilution of extracted DNA, $12.5 \mu \mathrm{L}$ SYBR-Green (Applied Biosystems Power SYBRGreen), 0.5 $\mu \mathrm{L}$ fluorescent dye, $0.5 \mu \mathrm{L}$ forward primer $(10 \mathrm{mM}), 0.5 \mu \mathrm{L}$ reverse prim-

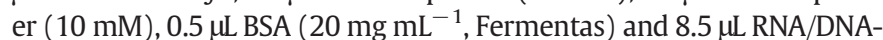
free water (Fermentas). The reaction mixture was transferred to a thin 96-well PCR plate with a micropipette. The plate was covered with optical-quality PCR caps (ABI, USA) and centrifuged briefly to bring all reagents to the bottom of the wells. Melting curve $\left(72-92{ }^{\circ} \mathrm{C}\right.$ ) analysis was conducted afterwards to determine the specificity of amplification. The average amplification efficiency of the specific qPCR primer set was $98 \%$ with an $r^{2}$ of 0.997 for the standard curve. The 16 S rRNA gene copies of total bacteria were also quantified using $16 \mathrm{~S}$ rRNA primer set S-DBact-0509-S-17/S-DBact-0784-A-22 (Table 2) according to the procedures described by Rupf et al. (1999). The relative abundance of M. parvicella could be calculated by dividing the 16S rRNA gene copy numbers of M. parvicella by that of total bacteria (Kaetzke et al., 2005).

\subsection{Fluorescence in situ hybridization}

It has to be taken into consideration that DNA studies deliver no direct information about microbe viability and that even inactive M. parvicella cells may promote foaming (de los Reyes et al., 2002). Thus, FISH was performed on ethanol-fixed activated sludge samples for Gram-positive bacteria. The fixed cells were sonicated for $60 \mathrm{~s}$ with an ultrasonic processor (Vibra-Cell, Sonics) at a pulse of $5 \mathrm{~s}$ and an output power of $4 \mathrm{~W}$ in order to break the sludge flocs and perform a better FISH quantification. The oligonucleotide probes EUB mix $_{\text {(equimolar con- }}$ centrations of EUB338, EUB338-II, and EUB338-III) labelled with fluo-

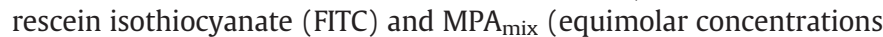
of MPA60, MPA223, and MPA645) labelled with the sulfoindocyanine dye Cy3 (Table 3), were used for FISH. In brief, each sample was diluted and homogenously spotted to the Teflon-coated 12-well slides. After hybridization, the slides were covered with ProLong® Gold Antifade Reagent (Thermo Fisher Scientific, USA). Detailed procedures were performed according to the protocols described by Nielsen et al. (2009) and stained images were captured with an Olympus BX51 epifluorescence microscope equipped with a cooled charged-coupled device (CCD) camera in true color using a suitable filter set and exposure times of a few milliseconds. At least 20 random fields at the magnification of 1000 were chosen to acquire images with a specific probedefined population and the general EUB $\mathrm{Bm}_{\text {mix }}$. The area of $M$. parvicella, relative to the total biomass area, was determined by image analyzing software (ImageJ, http://rsbweb.nih.gov/ij/). The standard deviation for all values and probes was between $16 \%$ and $20 \%$ of the average value indicated and only averages are shown in the figures. The percentage of FISH detectable cells was determined as the fraction of bacterial cells responding to probe $\mathrm{EUB}_{\text {mix }}$ over the total number of cells stained by 4'6-diamidino-2-phenylindole (DAPI) (Kapuscinski, 1995).

\subsection{Statistical analysis}

Statistical analysis to evaluate the effects of carbon source and environmental factors were performed using the SPSS16.0 software package (SPSS ${ }^{\circledR}$, Chicago, IL, USA). The $p$ values of 0.05 and 0.01 were regarded as the cutoff for statistical significance between two data sets.

\section{Results and discussion}

The key operating performance parameters are listed in Table 4. The average removal efficiencies for COD and ammonium nitrogen were 
Table 2

Primers used for the quantification of M. parvicella and total bacteria in this study.

\begin{tabular}{|c|c|c|c|}
\hline Primer & Target & Sequence $\left(5^{\prime}-3^{\prime}\right)$ & Reference \\
\hline S-D-Bact-0509-S-17 & Total bacteria & ACTACGTGCCAGCAGCC & (Rupf et al., 1999) $^{\mathrm{a}}$ \\
\hline S-D-Bact-0784-A-22 & & GGACTACCAGGGTATCTAATCC & \\
\hline S-S-M.par-0828-S-21 & Microthirix parvicella & GGTGTGGGGAGAACTCAACTC & (Kaetzke et al., 2005) ${ }^{\mathrm{b}}$ \\
\hline S-S-M.par-1018-A-17 & & GACCCCGAAGGACACCG & \\
\hline
\end{tabular}

a Rupf S, Merte K, Eschrich K (1999) Quantification of bacteria in oral samples by competitive polymerase chain reaction. J Dent Res 78(4):850-856.

b Kaetzke A, Jentzsch D, Eschrich K (2005) Quantification of Microthrix parvicella in activated sludge bacterial communities by real-time PCR. Lett Appl Microbiol 40(3):207-211.

$84.53 \%$ and $94.81 \%$, respectively, showing that each system was functioning well under different strategies.

\subsection{Influence of carbon source on M. parvicella growth}

As shown in Fig. 1, the average values of SVI decreased from $185 \mathrm{~mL} \mathrm{~g}^{-1}$ to $118 \mathrm{~mL} \mathrm{~g}^{-1}$ and $131 \mathrm{~mL} \mathrm{~g}^{-1}$, respectively, when mixed carbon source and acetate were fed in Phase I. However, the SVI was almost a constant value of $170 \mathrm{~mL} \mathrm{~g}^{-1}$ over the whole period when LCFA was used as the sole carbon source. As shown in Fig. 2a, the relative abundance of $M$. parvicella revealed by qPCR decreased very rapidly for the mixed carbon source and acetate systems, from around 33\% to $<5 \%$ within $60 \mathrm{~d}$. However, the relative abundance of $M$. parvicella for the LCFA system remained at a high level, ending at 36.7\%. Based on the absolute quantification results (Fig. S2), M. parvicella gene copy numbers in the LCFA system varied between $8.04 \times 10^{11}$ and 1.52 $\times 10^{12}$ gene copies $\mathrm{g}^{-1}$ sludge over the whole period, in comparison with $1.96 \times 10^{10}$ and $8.25 \times 10^{10}$ gene copies $g^{-1}$ sludge in the end for the other two carbon source systems. The FISH analysis results exhibited a very similar trend, as shown in Fig. $2 \mathrm{~b}$. The relative abundance of $M$. parvicella decreased from $36.17 \%$ to $3.62 \%$ and $5.28 \%$ respectively, for the mixed carbon source and acetate systems, while that of the LCFA system was $37.3 \%$. According to statistical analysis (Table 5), the LCFA system was significantly different from the other two systems in terms of $M$. parvicella abundance and SVI $(p<0.01)$. Microscopic examination results gave similar results (Fig. S3). The filamentous index (FI) of the LCFA system was an almost constant value of 5 , while those of the mixed carbon source and acetate systems decreased to 4 and 3, respectively. Even for the LCFA system, however, changes of filaments were observed. The length of filaments was shorter and hollow cells appeared in comparison with the initial state.

The behaviors of $M$. parvicella have been studied mainly through the observation of full-scale WWTP due to the difficulty in getting sufficient amounts of pure culture biomass. In this study, three strategies, the preferences of M. parvicella for carbon sources, aerobic/anaerobic alternation and temperature, were evaluated by using activated sludge under bulking state as seed sludge. As shown in Figs. 1 and 2, the SVI values decreased quickly together with the relative abundance of
M. parvicella when the carbon sources did not contain oily compounds. However, both the SVI value and the abundance of M. parvicella were almost constant over a period of two months when LCFA was used as the carbon source. Thus, the presence of hydrophobic compounds in wastewater seems to be an important condition in keeping the growth of M. parvicella in activated sludge. Hydrophobic compounds including lipids and LCFA have been reported to constitute $15-40 \%$ of total COD in municipal wastewater (Dueholm et al., 2000; Henze et al., 1994; Quéméneur and Marty, 1994). The ability of M. parvicella to take up LCFA has been documented for both mixed culture (Andreasen and Nielsen, 1998; Mamais et al., 1998) and pure culture (Slijkhuis, 1983a; Slijkhuis and Deinema, 1988). By using the MAC-test Nielsen et al. (2002) found that compared to other unidentified filamentous bacteria, M. parvicella was more hydrophobic, allowing lipids and LCFA to be preferably adsorbed to its cells. At the same time, by using an enzymelinked fluorescence method the presence of lipases was identified on the cell surface of M. parvicella, which also make it easier to take up the hydrophobic compounds (Nielsen et al., 2012).

\subsection{Influence of anaerobic/aerobic alternation on M. parvicella growth}

By employing LCFA as the sole carbon source, the aerobic strategy was compared with the anaerobic/aerobic alternation strategy in Phase II. As indicated in Table 4, ammonium nitrogen was almost completely transformed into nitrate in the aerobic stage. A part of nitrate $(\sim 30 \%)$ was decomposed into nitrogen gas in the anaerobic stage because some treated water was decanted after aerobic treatment. No significant changes of phosphate were observed.

In the aerobic system, the SVI value decreased from $182.5 \mathrm{~mL} \mathrm{~g}^{-1}$ to $65.5 \mathrm{~mL} \mathrm{~g}^{-1}$, while the SVI value only decreased slightly to $163 \mathrm{~mL} \mathrm{~g}^{-1}$ in the anaerobic/aerobic alternation system (Fig. 1). Both FISH and qPCR results showed that the relative abundance of $M$. parvicella decreased in the two systems over the experimental period (Fig. 2). The relative abundance of $M$. parvicella revealed by qPCR decreased from around $26.52 \%$ to $0.7 \%$ and $9.74 \%$, respectively for the aerobic and aerobic/anaerobic alternation systems over the experimental period. However, the relative abundance of $M$. parvicella remained almost constant from Day 40 on (Fig. 2a). According to absolute qPCR results (Fig. S2), the

Table 3

The oligonucleotide probes for M. parvicella and total bacteria.

\begin{tabular}{|c|c|c|c|c|c|}
\hline Probe & Target & Sequence $\left(5^{\prime}-3^{\prime}\right)$ & Target site (16S rRNA position) & Fluorochrome labelled & Reference \\
\hline $\mathrm{EUB}_{\text {mix }}$ & Total bacteria & $\begin{array}{l}\text { EUB338:GCTGCCTCCCGTAGGAGT } \\
\text { EUB338-II:GCAGCCACCCGTAGGTGT } \\
\text { EUB338-III:GCTGCCACCCGTAGGTGT }\end{array}$ & $338-355$ & FITC & (Amann et al., 1990) \\
\hline $\mathrm{MPA}_{\operatorname{mix}}$ & Microthrix parvicella & $\begin{array}{l}\text { MPA60:GGA TGGCCGCGTTCGACT } \\
\text { MPA223:GCCGCGAGACCCTCCTAG } \\
\text { MPA645:CCGGACTCTAGTCAGAGC }\end{array}$ & $\begin{array}{l}60-77 \\
223-240 \\
645-661\end{array}$ & Су3 & $\left(\right.$ Erhart et al., 1997) ${ }^{\mathrm{b}}$ \\
\hline
\end{tabular}

a Amann RI, Binder BJ, Olson RJ, Chisholm SW, Devereux R, Stahl DA (1990) Combination of 16S rRNA-targeted oligonucleotide probes with flow cytometry for analyzing mixed microbial populations. Appl Environ Microb 56(6):1919-1925.

b Erhart R, Bradford D, Seviour RJ, Amann R, Blackall LL (1997) Development and use of fluorescent in situ hybridization probes for the detection and identification of "Microthrix parvicella" in activated sludge. System Appl Microbiol 20(2):310-318. 
Table 4

The overall performance of batch experiments under different operating conditions (mean \pm standard deviation).

\begin{tabular}{|c|c|c|c|c|c|c|c|c|c|}
\hline \multirow[t]{2}{*}{ Experimental systems } & \multirow{2}{*}{$\frac{\text { MLSS }}{\left(\mathrm{g} \mathrm{L}^{-1}\right)}$} & \multicolumn{2}{|c|}{$\mathrm{COD}\left(\mathrm{mg} \mathrm{L}^{-1}\right)$} & \multicolumn{2}{|c|}{$\mathrm{NH}_{4}^{+}-\mathrm{N}\left(\mathrm{mg} \mathrm{L}^{-1}\right)$} & \multicolumn{2}{|c|}{$\mathrm{NO}_{3}^{-}-\mathrm{N}\left(\mathrm{mg} \mathrm{L}^{-1}\right)$} & \multicolumn{2}{|c|}{$\mathrm{PO}_{3}^{3-}-\mathrm{P}\left(\mathrm{mg} \mathrm{L}^{-1}\right)$} \\
\hline & & Influent & Effluent & Influent & Effluent & Influent & Effluent & Influent & Effluent \\
\hline \multicolumn{10}{|l|}{ Phase I } \\
\hline Mixed carbon source & $5.1 \pm 0.4$ & $224 \pm 29$ & $41 \pm 10$ & $12.6 \pm 0.9$ & $0.8 \pm 0.6$ & $\sim 0$ & $14.8 \pm 2.7$ & $4.8 \pm 1.5$ & $5.6 \pm 2.3$ \\
\hline $\mathrm{NaAc}$ & $5.0 \pm 0.6$ & $231 \pm 24$ & $32 \pm 5$ & $11.9 \pm 1.3$ & $0.4 \pm 0.2$ & $\sim 0$ & $11.6 \pm 1.4$ & $4.4 \pm 1.8$ & $6.1 \pm 1.9$ \\
\hline LCFA & $5.0 \pm 0.4$ & $216 \pm 19$ & $32 \pm 4$ & $12.4 \pm 1.1$ & $1.0 \pm 0.7$ & $\sim 0$ & $16.5 \pm 3.4$ & $4.5 \pm 1.0$ & $5.5 \pm 2.5$ \\
\hline \multicolumn{10}{|l|}{ Phase II } \\
\hline Aerobic & $3.8 \pm 0.7$ & $226 \pm 35$ & $32 \pm 10$ & $16.1 \pm 2.1$ & $0.5 \pm 0.3$ & $\sim 0$ & $19.8 \pm 3.5$ & $4.6 \pm 0.7$ & $4.8 \pm 0.7$ \\
\hline Anaerobic/Aerobic & $3.8 \pm 0.6$ & $247 \pm 29$ & $40 \pm 15$ & $16.2 \pm 1.6$ & $0.6 \pm 0.2$ & $\sim 0$ & $14.5 \pm 2.2$ & $3.9 \pm 0.8$ & $3.8 \pm 1.2$ \\
\hline \multicolumn{10}{|l|}{ Phase III } \\
\hline $13^{\circ} \mathrm{C}$ & $3.2 \pm 0.9$ & $232 \pm 29$ & $37 \pm 15$ & $14.5 \pm 3.0$ & $0.6 \pm 0.1$ & $\sim 0$ & $14.8 \pm 3.2$ & $3.8 \pm 0.3$ & $4.2 \pm 1.5$ \\
\hline $20^{\circ} \mathrm{C}$ & $3.4 \pm 0.6$ & $253 \pm 33$ & $38 \pm 16$ & $12.9 \pm 2.4$ & $0.7 \pm 0.8$ & $\sim 0$ & $12.5 \pm 2.7$ & $4.4 \pm 0.5$ & $5.0 \pm 1.7$ \\
\hline
\end{tabular}

M. parvicella gene copy numbers in the aerobic/anaerobic alternation system decreased from around $1.09 \times 10^{12}$ gene copies $\mathrm{g}^{-1}$ sludge to $9.70 \times 10^{10}$ gene copies $\mathrm{g}^{-1}$ sludge in the end of the experiment,
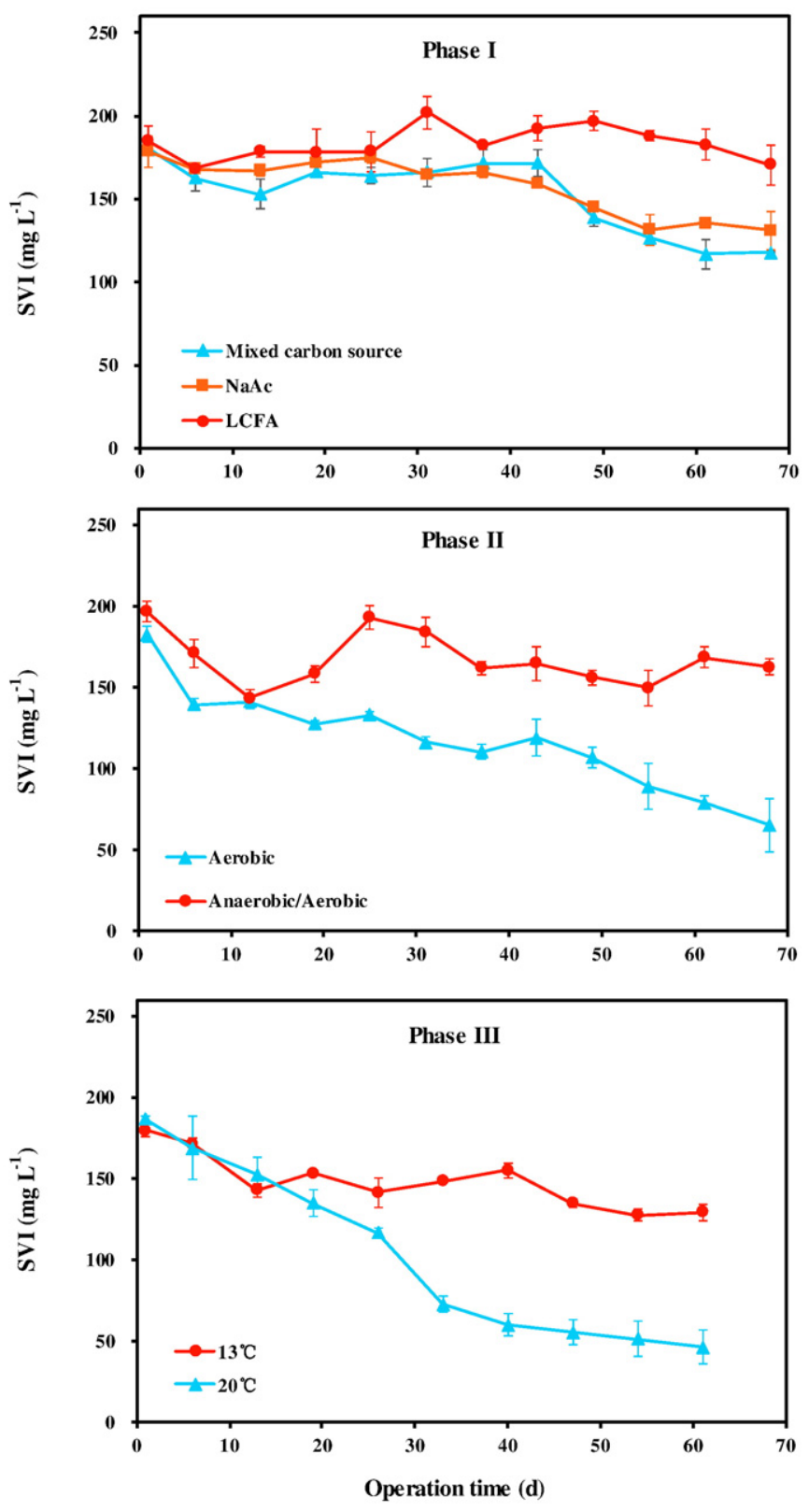

Fig. 1. SVI changes in three phases. while that in the aerobic system decreased to a level of 4.47 $\times 10^{9}$ gene copies $\mathrm{g}^{-1}$ sludge. As shown in Fig. $2 \mathrm{~b}$, the relative abundances of $M$. parvicella revealed by FISH decreased from $43.64 \%$ to $2.2 \%$ and $16.4 \%$, respectively, for the aerobic and aerobic/anaerobic alternation systems. According to statistical analysis (Table 5), the aerobic system was significantly different $(p<0.01)$ from the aerobic/anaerobic alternation one in terms of M. parvicella abundance and SVI. Microscopic examination results showed that the FI value dramatically decreased to 2.5 in the aerobic system, while the FI value was 4 in the aerobic/anaerobic alternation one (Fig. S4). The Gram staining images showed that some filaments became short and hollow inside in both systems.

In comparison with the aerobic system, the anaerobic/aerobic alternation system allowed a much higher presence of the filamentous bacteria, as shown in Fig. 2, suggesting the advantage of the anaerobic/ aerobic alternation condition in keeping the dominant position of M. parvicella in activated sludge. This result may explain why M. parvicella-caused sludge bulking normally occurred in biological nutrient removal processes containing at least one anaerobic/aerobic alternation (Rossetti et al., 2005). An in situ investigation (Andreasen and Nielsen, 2000) indicated that M. parvicella had a considerable capacity to take up oleic acid under aerobic, anoxic or anaerobic conditions, with the most significant uptake occurring under the anaerobic condition. However, the uptake of LCFA for other filaments and floc formers was significantly diminished or even lost in the absence of aerobic conditions. According to a metabolic model of $M$. parvicella established by Mcllroy et al. (2013), LCFAs were accumulated as neutral lipids (triacylglycerides, TAGs) under the anaerobic condition, and subsequently processed in the oxidative tricarboxylic acid (TCA) cycle, providing energy and intermediates required for $M$. parvicella growth under aerobic conditions. Thus, the presence of anaerobic condition may provide $M$. parvicella an advantage against other bacteria which do not possess storage capacity under such conditions.

It should be noted that the aerobic system in Phase II was almost the same with the LCFA system in Phase I in terms of the operational conditions and carbon source. However, the growth states of $M$. parvicella were significantly different. The only difference for the two systems was the inocula. In Phase II, seed sludge was collected on 11th March when sludge bulking had passed the peak, and the abundance of active M. parvicella was beginning to decrease, suggesting that $M$. parvicella might have entered its decline phase. Microscopic observation results (Fig. S5) showed that M. parvicella was in a healthy state with long and regular filaments in the seed sludge of Phase I, because sludge bulking was just beginning in the full-scale WWTP. Some empty or deformed cells of filamentous bacteria were observed in the seed sludge of Phase II although the SVI value was the highest in mid-March (Fig. S6). It seemed that the decay trend of $M$. parvicella could not easily be reversed. On the other hand, cultures of M. parvicella could grow over a wide range of oxygen partial pressures, but good growth was obtained under microaerophilic conditions (Rossetti et al., 2005). High DO concentration ( $>6 \mathrm{mg} \mathrm{L}^{-1}$ ) might be toxic to this microorganism 


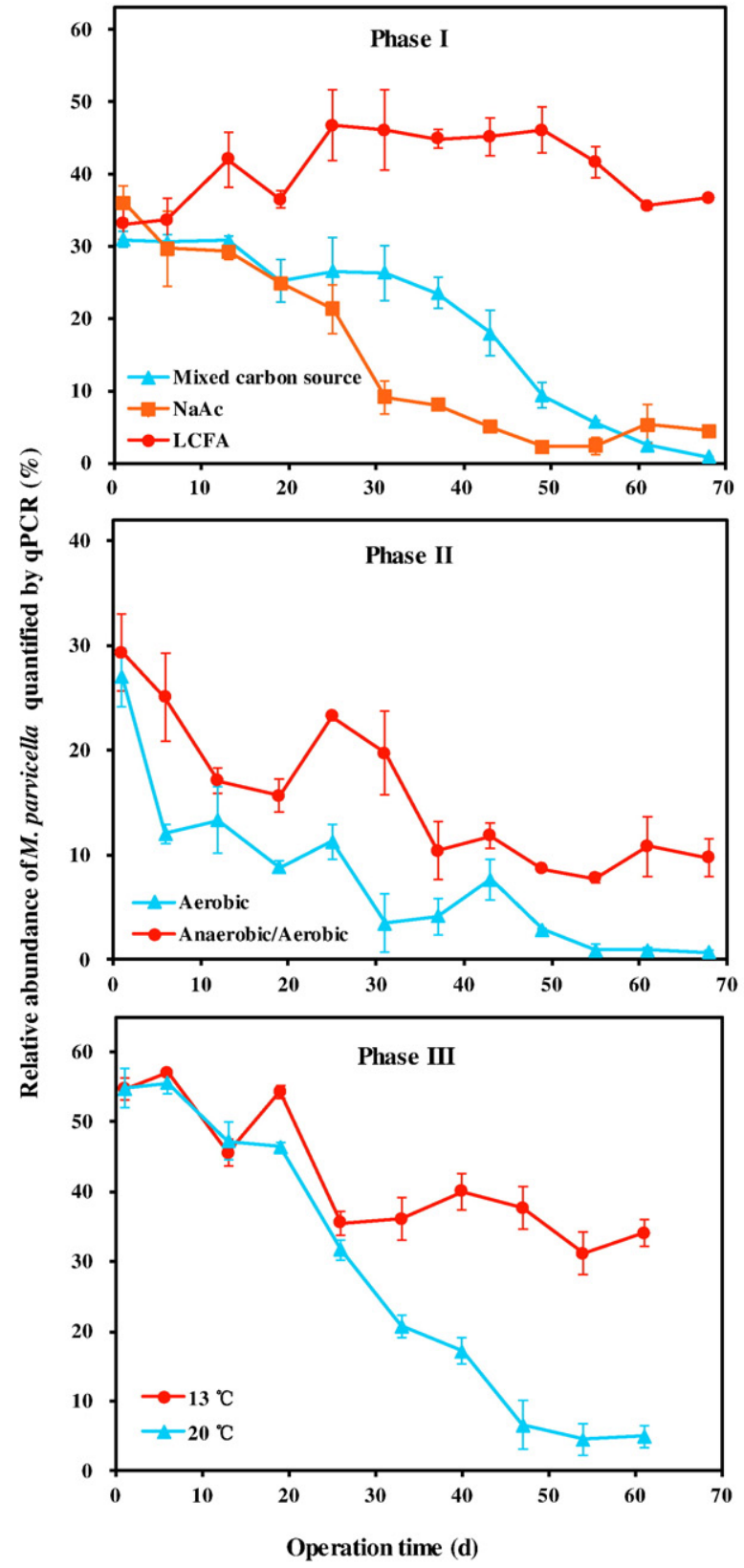

(a)

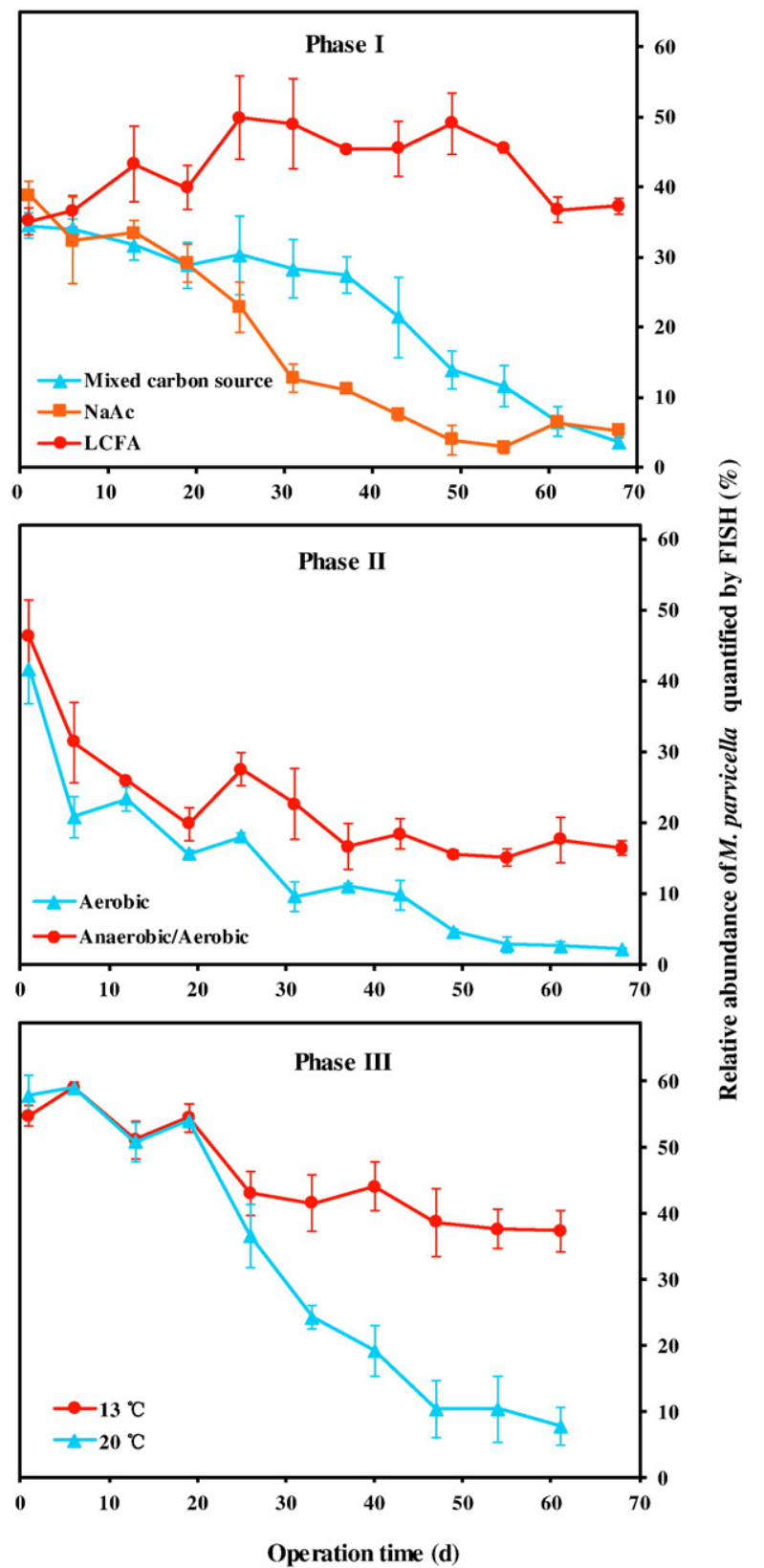

(b)

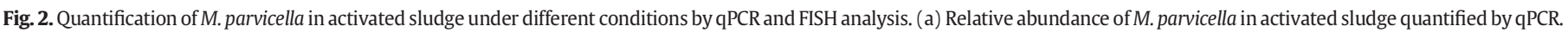
(b) Relative abundance of $M$. parvicella in activated sludge quantified by FISH analysis.

Table 5

The $t$-test results of batch experiment

\begin{tabular}{llllll}
\hline Experimental phases & Group & & & & \\
& & & value $^{\mathrm{b}}$ & & \\
\cline { 4 - 6 } & & & qPCR & FISH & SVI \\
\hline Phase I & Mixed & NaAc & 0.0678 & 0.0564 & 0.0851 \\
& Mixed & LCFA & 0.0077 & 0.0002 & 0.0007 \\
& NaAc & LCFA & 0.0016 & 0.0001 & 0.0012 \\
Phase II & Aerobic & Altern & 0.0028 & 0.0001 & 0.0001 \\
Phase III & $13^{\circ} \mathrm{C}$ & $20{ }^{\circ} \mathrm{C}$ & 0.0255 & 0.0137 & 0.0087 \\
\hline
\end{tabular}

Note: $p>0.05$, there is no significant difference between two groups; $0.01<p<0.05$, there is a significant difference between two groups; $p<0.01$, there is a highly significant difference between two groups (Holm, 1979).

a 'Mixed' is mixed carbon source and 'Altern' is anaerobic/aerobic alternative condition.

b $p$ value reflects the significance of the difference between two groups.
(Slijkhuis, 1983b). The DO values in aerobic condition of Phase I (5.8 $\mathrm{mg} \mathrm{L}^{-1}$ ) and Phase II $\left(6.7 \mathrm{mg} \mathrm{L}^{-1}\right.$ ) were quite similar. The effects of DO on M. parvicella growth, however, could not be excluded since DO was not strictly controlled over the whole experimental period.

\subsection{Influence of temperature on M. parvicella growth}

By employing LCFA as the sole carbon source and adopting the anaerobic/aerobic alternation strategy, the influence of temperature on M. parvicella growth was investigated in Phase III. At a temperature of $20{ }^{\circ} \mathrm{C}$, the SVI value decreased quickly from $183.2 \mathrm{~mL} \mathrm{~g}^{-1}$ to $46.5 \mathrm{~mL} \mathrm{~g}^{-1}$, while the SVI value was $129.5 \mathrm{~mL} \mathrm{~g}^{-1}$ in the end at 13 ${ }^{\circ} \mathrm{C}$. Similar to the trend of SVI, the relative abundances of M. parvicella were found to decrease from around $54.70 \%$ to $34.07 \%$ and $4.94 \%$, and from around $56.41 \%$ to $37.38 \%$ and $7.88 \%$, respectively, by using FISH 
and qPCR methods for the $13{ }^{\circ} \mathrm{C}$ and $20^{\circ} \mathrm{C}$ systems (Fig. 2). In addition, the $M$. parvicella gene copy numbers in activated sludge decreased from $8.21 \times 10^{11}$ to $2.36 \times 10^{11}$ in the $13^{\circ} \mathrm{C}$ system, and from $1.29 \times 10^{12}$ to $1.41 \times 10^{10}$ gene copies $\mathrm{g}^{-1}$ sludge in the $20^{\circ} \mathrm{C}$ system (Fig. S2). According to statistical analysis (Table 5), the $13{ }^{\circ} \mathrm{C}$ system was significantly different $(p<0.05)$ from the $20^{\circ} \mathrm{C}$ one in terms of $M$. parvicella abundance and SVI. Microscopic examination results (Fig. S7) showed that the FI value dramatically decreased from 5 to 2 at $20^{\circ} \mathrm{C}$, while the FI value was kept at 4 at $13^{\circ} \mathrm{C}$. The Gram staining images showed the presence of short and hollow filaments after around two-month operation, and the sludge flocs were relatively compact with lower abundance of filaments extending outside.

Among various factors inducing filamentous sludge bulking, temperature seems to be correlated with the changes in both SVI and M. parvicella abundance in activated sludge (Wang et al., 2014). This study showed that a low temperature $\left(13^{\circ} \mathrm{C}\right)$ favored keeping a high relative abundance of $M$. parvicella. Though the optimal temperature for M. parvicella was determined to be $25{ }^{\circ} \mathrm{C}$ using pure cultures (Slijkhuis, 1983a), most previously sludge bulking events caused by M. parvicella mainly occurred at a low temperature (Miana et al., 2002; Wanner, 1994). The low temperature preference of $M$. parvicella has already been reported both in a full-scale plant and in a laboratory system. Knoop and Kunst (1998) found that M. parvicella could grow well in long and active filaments at low temperature around $12{ }^{\circ} \mathrm{C}$ and destruction of filament structure appeared in a lab-scale system with the increase of temperature from $12{ }^{\circ} \mathrm{C}$ to $20^{\circ} \mathrm{C}$. M. parvicella may produce enzymes that could destroy its cell wall in warmer water $\left(>20^{\circ} \mathrm{C}\right)$ (Franz and Matsche, 1994; Pitman, 1996). Cold climate in winter and spring was regarded as the main stimulator for the dominant growth of M. parvicella (Pitman, 1996). The growth rate of M. parvicella was still quite high even when the temperature was as low as $7{ }^{\circ} \mathrm{C}$, while the bioactivity of most bacteria dramatically decreased at such a low temperature (Rossetti et al., 2002). Sheik et al. (2016) also performed temperature-dependent incubation experiments under aerobic conditions over wide range of temperatures $\left(4-35{ }^{\circ} \mathrm{C}\right)$ and compared M. parvicella ${ }^{13} \mathrm{C}$-oleic acid assimilation rates at the $5 \mathrm{~h}$ time point. The observed two temperature optima $\left(4^{\circ} \mathrm{C}\right.$ and $\left.25^{\circ} \mathrm{C}\right)$ may be attributed to the differences in the bioavailability of ${ }^{13} \mathrm{C}$-oleic acid (higher levels of bioavailability are expected at the lower temperatures) (Rossetti et al., 2005) and the altered activity of the acyl-CoA ligases for ${ }^{13} \mathrm{C}$ oleic acid assimilation (higher assimilation rates might be expected at the higher temperature). Therefore, it is obvious that low temperature contributes to the competitive advantage of $M$. parvicella in activated sludge. However, it is still dubious to conclude whether low temperature stimulates the growth of $M$. parvicella, or just slows down its death rate by inhibiting metabolic rate; more knowledge is needed about the low-temperature response mechanism and ecophysiology of M. parvicella.

Correlations between SVI and M. parvicella abundance were calculated, as shown in Table 6. As a result, significant positive correlations ( $p<$ 0.05 ) were observed, which was in accordance with some previous studies (Kaetzke et al., 2005; Kumari et al., 2009b). Moreover, highly significant correlation $(r=0.964, p<0.01)$ was also observed between
SVI and M. parvicella abundance for sludge from Xiaohongmen WWTP (seed sludge source) over the sampling period.

Although SVI is a convenient parameter to monitor the state of activated sludge in practice, it should be noted that it could not fully reflect the dynamic state of sludge bulking. Some studies have demonstrated poor correlation between SVI and filamentous bacteria (ValverdePérez et al., 2016). Recently, some other parameters, such as yield stress parameter and floc strength factor, have been used to better represent the bulking state of sludge (Burger et al., 2017; Wágner et al., 2015).

\section{Conclusion}

Though the preferences of M. parvicella for carbon sources, aerobic/ anaerobic alternation and temperature were confirmed in this study by using bulking activated sludge as seed sludge, we could not find a condition to further enrich M. parvicella. At the same time, the three phases of the experiments were performed using seed sludge collected in different bulking stages, which makes it difficult to compare the results in different experimental phases. Besides, the HRT and SRT adopted in this study were much longer than real WWTPs, which might affect the bacterial population. In order to better understand the factors affecting the growth of $M$. parvicella, further studies are required to perform the experiments using the same seed sludge and rational technological parameters.

In conclusion, this study investigated the effects of carbon source, anaerobic/aerobic conditions and temperature on the growth of the filamentous bacterium M. parvicella in batch-scale systems by using seed sludge collected from a full-scale WWTP suffering sludge bulking. It was revealed for the first time that integrated conditions including the use of LCFA as carbon source, anaerobic/aerobic alternation treatment and low temperature favored the survival of M. parvicella, which laid a foundation for subsequent pure culture study. However, more investigations are required to rich the knowledge on physiology and metabolism of M. parvicella.

\section{Acknowledgments}

The authors are grateful for the financial support from the Natural Science Foundation of China (Grant No. 51378489 and Grant No. 31170468). This work was supported by the Free Exchange Programs between the University of Chinese Academy of Sciences and the Italian National Research Council.

\section{Conflict of interest}

The authors declare that they have no conflict of interest.

\section{Appendix A. Supplementary data}

Supplementary data to this article can be found online at http://dx. doi.org/10.1016/j.scitotenv.2017.07.261.

Table 6

The correlation between SVI and M. parvicella abundance in three phases.

\begin{tabular}{|c|c|c|c|c|c|c|c|}
\hline \multirow[t]{2}{*}{ Correlation coefficient } & \multicolumn{3}{|c|}{ Carbon source } & \multicolumn{2}{|c|}{ Aerobic/Anaerobic } & \multicolumn{2}{|c|}{ Temperature } \\
\hline & Mixed & $\mathrm{NaAc}$ & LCFA & Aerobic & Aerobic/Anaerobic & $13^{\circ} \mathrm{C}$ & $20^{\circ} \mathrm{C}$ \\
\hline$r^{\mathrm{a}}$ & 0.883 & 0.867 & 0.473 & 0.993 & 0.699 & 0.879 & 0.976 \\
\hline$p^{\mathrm{b}}$ & $<0.001^{* *}$ & $<0.001^{* *}$ & 0.121 & $<0.001^{* *}$ & $0.011^{*}$ & $0.001^{* *}$ & $<0.001^{* *}$ \\
\hline
\end{tabular}

Note: $p<0.01$, highly significant correlation; $0.01<p<0.05$, significant correlation.

a $r$ is the correlation coefficient. $r>0$, positive correlation; $r<0$, negative correlation.

b $p$ is the significant coefficient. 


\section{References}

Amann, R.I., Binder, B.J., Olson, RJ. Chisholm, S.W., Devereux, R, Stahl, D.A., 1990. Combination of 16S rRNA-targeted oligonucleotide probes with flow cytometry for analyzing mixed microbial populations. Appl. Environ. Microbiol. 56, 1919-1925.

Andreasen, K., Nielsen, P.H., 1998. In situ characterization of substrate uptake by Microthrix parvicella using microautoradiography. Water Sci. Technol. 37, 19-26.

Andreasen, K., Nielsen, P.H., 2000. Growth of Microthrix parvicella in nutrient removal activated sludge plants: studies of in situ physiology. Water Res. 34, 1559-1569.

Bru, D., Martin-Laurent, F., Philippot, L., 2008. Quantification of the detrimental effect of a single primer-template mismatch by real-time PCR using the 16S rRNA gene as an example. Appl. Environ. Microbiol. 74, 1660-1663.

Burger, W., Krysiak-Baltyn, K., Scales, P.J., Martin, G.J., Stickland, A.D., Gras, S.L., 2017. The influence of protruding filamentous bacteria on floc stability and solid-liquid separation in the activated sludge process. Water Res.

Dueholm, T., Andreasen, K., Nielsen, P.H., 2000. Transformation of lipids in activated sludge. Water Sci. Technol. 43, 165-172.

Eaton, A.D., Clesceri, L., Rice, E., Greenberg, A., Franson, M., Franson, M.A.H., Clesceri, L.S Rice, E., Greenberg, A.S., 2005. Standard Methods for the Examination of Water and Wastewater. 21st Ed. Washington, DC, USA, American Public Health Association (APHA).

Eikelboom, D.H., Andreadakis, A., Andreasen, K., 1998. Survey of filamentous populations in nutrient removal plants in four European countries. Water Sci. Technol. 37, 281-289.

Erhart, R., Bradford, D., Seviour, R.J., Amann, R., Blackall, L.L., 1997. Development and use of fluorescent in situ hybridization probes for the detection and identification of "Microthrix parvicella" in activated sludge. Syst. Appl. Microbiol. 20, 310-318.

Franz, A., Matsche, N., 1994. Investigation of a bacteria-enzyme additive to prevent foaming in activated sludge plants. Water Sci. Technol. 29, 281-284.

Henze, M., Kristensen, G.H., Strube, R., 1994. Rate-capacity characterization of wastewater for nutrient removal processes. Water Sci. Technol. 29, 101-107.

Holm, S., 1979. A simple sequentially rejective multiple test procedure. Scand. J. Stat. 6 $65-70$.

Hucker, G.J., Conn, H.J., 1923. Methods of Gram Staining.

Jenkins, D. Richard, M.G. Daigger, G.T. 1993. Manual on the causes and control of activated sludge bulking and foaming. 2. Manual on the Causes and Control of Activated Sludge Bulking and Foaming. 2. ed. Lewis.

Kaetzke, A., Jentzsch, D., Eschrich, K., 2005. Quantification of Microthrix parvicella in activated sludge bacterial communities by real-time PCR. Lett. Appl. Microbiol. 40, 207-211.

Kapuscinski, J., 1995. DAPI: a DNA-specific fluorescent probe. Biotech. Histochem. 70, 220-233.

Knoop, S., Kunst, S., 1998. Influence of temperature and sludge loading on activated sludge settling, especially on Microthrix parvicella. Water Sci. Technol. 37, 27-35.

Kumari, S.K.S., Marrengane, Z., Bux, F., 2009a. Application of quantitative RT-PCR to determine the distribution of Microthrix parvicella in full-scale activated sludge treatment systems. Appl. Microbiol. Biotechnol. 83, 1135-1141.

Kumari, S.K.S., Marrengane, Z., Bux, F., 2009b. Application of quantitative RT-PCR to determine the distribution of Microthrix parvicella in full-scale activated sludge treatment systems. Appl. Microbiol. Biotechnol. 83, 1135-1141.

Mamais, D., Andreadakis, A., Noutsopoulos, C., Kalergis, C., 1998. Causes of, and control strategies for, Microthrix parvicella bulking and foaming in nutrient removal activated sludge systems. Water Sci. Technol. 37, 9-17.

Marneri, M., Mamais, D., Koutsiouki, E., 2009. Microthrix parvicella and Gordona amarae in mesophilic and thermophilic anaerobic digestion systems. Environ. Technol. 30, 437-444.

McIlroy, S.J., Kristiansen, R., Albertsen, M., Karst, S.M., Rossetti, S., Nielsen, J.L., Tandoi, V., Seviour, R.J., Nielsen, P.H., 2013. Metabolic model for the filamentous 'Candidatus Microthrix parvicella' based on genomic and metagenomic analyses. ISME J. 7, 1161-1172.

Miana, P., Grando, L., Caravello, G., Fabris, M., 2002. Microthrix parvicella foaming at the Fusina WWTP. Water Sci. Technol. 46, 499-502.
Nielsen, P.H., Roslev, P., Dueholm, T.E., Nielsen, J.L., 2002. Microthrix parvicella, a specialized lipid consumer in anaerobic-aerobic activated sludge plants. Water Sci. Technol. $46,73-80$

Nielsen, P.H., Kragelund, C., Seviour, R.J., Nielsen, J.L., 2009. Identity and ecophysiology of filamentous bacteria in activated sludge. FEMS Microbiol. Rev. 33, 969-998.

Nielsen, P.H., Saunders, A.M., Hansen, A.A., Larsen, P., Nielsen, J.L., 2012. Microbial communities involved in enhanced biological phosphorus removal from wastewater-a model system in environmental biotechnology. Curr. Opin. Biotechnol. 23, 452-459.

Noutsopoulos, C., Mamais, D., Andreadakis, A., 2012. A hypothesis on Microthrix parvicella proliferation in biological nutrient removal activated sludge systems with selector tanks. FEMS Microbiol. Ecol. 80, 380-389.

Pei, R., Kim, S.C., Carlson, K.H., Pruden, A., 2006. Effect of river landscape on the sediment concentrations of antibiotics and corresponding antibiotic resistance genes (ARG). Water Res. 40, 2427-2435.

Pitman, A.R., 1996. Bulking and foaming in BNR plants in Johannesburg: problems and solutions. Water Sci. Technol. 34, 291-298.

Quéméneur, M., Marty, Y., 1994. Fatty acids and sterols in domestic wastewaters. Water Res. 28, 1217-1226.

de los Reyes, F.L., Rothauszky, D., Raskin, L., 2002. Microbial community structures in foaming and nonfoaming full-scale wastewater treatment plants. Water Environ. Res. 74, 437-449.

Rossetti, S., Carucci, A., Rolle, E., 1994. Survey on the occurrence of filamentous organisms in municipal wastewater treatment plants related to their operating conditions. Water Sci. Technol. 29, 305-308.

Rossetti, S., Christensson, C., Blackall, L.L., Tandoi, V., 1997. Phenotypic and phylogenetic description of an Italian isolate of "Microthrix parvicella". J. Appl. Microbiol. 82, 405-410.

Rossetti, S., Tomei, M.C., Levantesi, C., Ramadori, R., Tandoi, V., 2002. Microthrix parvicella: a new approach for kinetic and physiological characterization. Water Sci. Technol. 46, $65-72$.

Rossetti, S., Tomei, M.C., Nielsen, P.H., Tandoi, V., 2005. “Microthrix parvicella”, a filamentous bacterium causing bulking and foaming in activated sludge systems: a review of current knowledge. FEMS Microbiol. Rev. 29, 49-64.

Rupf, S., Merte, K., Eschrich, K., 1999. Quantification of bacteria in oral samples by competitive polymerase chain reaction. J. Dent. Res. 78, 850-856.

Sheik, A.R., Muller, E.E., Audinot, J.N., Lebrun, L.A., Grysan, P., Guignard, C., Wilmes, P., 2016. In situ phenotypic heterogeneity among single cells of the filamentous bacterium Candidatus Microthrix parvicella. ISME J. 10, 1274-1279.

Slijkhuis, H., 1983a. Microthrix parvicella, a filamentous bacterium isolated from activated sludge: cultivation in a chemically defined medium. Appl. Environ. Microbiol. 46, 832-839.

Slijkhuis, H., 1983b. The Physiology of the Filamentous Bacterium Microthrix parvicella. Landbouwhogeschool Press.

Slijkhuis, H., Deinema, M.H., 1988. Effect of environmental conditions on the occurrence of Microthrix parvicella in activated sludge. Water Res. 22, 825-828

Valverde-Pérez, B., Wágner, D.S., Lóránt, B., Gülay, A., Smets, B.F., Plósz, B.G., 2016. Shortsludge age EBPR process-microbial and biochemical process characterisation during reactor start-up and operation. Water Res. 104, 320-329.

Wagner, M., Erhart, R., Manz, W., Amann, R., Lemmer, H., Wedi, D., Schleifer, K.H., 1994. Development of an rRNA-targeted oligonucleotide probe specific for the genus Acinetobacter and its application for in situ monitoring in activated sludge. Appl. Environ. Microbiol. 60, 792-800.

Wágner, D.S., Ramin, E., Szabo, P., Dechesne, A., Plósz, B.G., 2015. Microthrix parvicella abundance associates with activated sludge settling velocity and rheologyquantifying and modelling filamentous bulking. Water Res. 78, 121-132.

Wang, J., Li, Q., Qi, R., Tandoi, V., Yang, M., 2014. Sludge bulking impact on relevant bacterial populations in a full-scale municipal wastewater treatment plant. Process Biochem. 49, 2258-2265.

Wanner, J., 1994. Activated Sludge: Bulking and Foaming Control. CRC Press.

Westlund, Å.D., Hagland, E., Rothman, M., 1998. Foaming in anaerobic digesters caused by Microthrix parvicella. Water Sci. Technol. 37, 51-55. 